\title{
COMUNICAÇÃO GRÁFICA DA MARCA ROSAMEL: UM ESTUDO DESCRITIV0-INTERPRETATIVO
}

COMMUNICATION GRAPHICS BRAND ROSAMEL: A CASE STUDY DESCRIPTIVE-INTERPRETIVE

\author{
por Raquel Gularte Queiroz, Richard Perassi Luiz de Souza
}

e Sharlene Melanie Martins de Araújo

RESUMO

0 artigo apresenta uma pesquisa realizada junto à marca "RosaMel", que representa um pequeno negócio da cidade de Florianópolis, SC, que produz e comercializa pães de mel, bolos e alfajores, entre outros. 0 primeiro nome da marca, "Rosa", é parte do nome da empreendedora e, o segundo, mel, indica que quase a totalidade dos produtos é caracterizada pelo uso da substância mel natural em sua composição. Isso caracteriza um nome poético e coerente com a natureza do negócio. Todavia, falta-lhe um projeto de identidade visual que reforce essa coerência e confirme os valores da marca. Além disso, considera-se que o caso estudado, com base em pesquisa descritiva, é semelhante à situação de diversos outros pequenos negócios brasileiros no setor de alimentos artesanais. Portanto, serve de exemplo da necessidade e das possibilidades de aplicação dos conhecimentos da área de Gestão de Design para o desenvolvimento desse tipo de empreendimento.

Palavras-chave: Gestão de Design, Design Gráfico, Branding

\section{ABSTRACT}

The article presents a survey conducted by the brand "RosaMel", which is a small business in the city of Florianópolis, SC, that produces and sells honey buns, cakes and alfajores, and others. The first name of the brand, "Rosa", is part of the name of the enterprising and, the second, "Mel", implies that nearly all products use honey in its natural composition. It features a poetic name and consistent with the nature of business. However, lacks a visual identity project that reinforces that consistency and confirm the values of the brand. Furthermore, it is considered that the case study, based on descriptive research, is similar to the situation in many other small brazilian businesses, from the artisan food sector. Therefore, serves as an example of the need possible application of knowledge in the area of Management Design for the development of this type of venture.

Keywords: Management Design, Graphic Design, Dranding 


\section{COMUNICAÇÃO GRÁFICA DA MARCA ROSAMEL: \\ UM ESTUDO DESCRITIVO-INTERPRETATIVO}

\section{Introdução}

Este artigo é resultante dos estudos realizados durante o curso de Especialização em Gestão de Design (NGD/Pós-Design/UFSC, 2010) e trata da gestão do design em ações de empreendedorismo individual no desenvolvimento de pequenos negócios. 0 foco recai, primeiramente, sobre a área de Design Gráfico, no tocante ao planejamento da identidade visual e da comunicação gráfica da marca comercial. 0 que é apresentado neste texto é o relatório descritivo-interpretativo sobre o caso da empresa de produtos alimentícios RosaMel. Considera-se que este caso específico retrata de maneira geral a situação de diversas marcas que se estabeleceram a partir de ações de empreendedorismo individual que configuram pequenos negócios.

"RosaMel" é a marca de um negócio do ramo alimentício em processo de formalização na cidade de Florianópolis, SC. No ano de 2005, foi caracterizado o início das atividades intencionalmente voltadas para o mercado. 0 negócio é decorrência de uma ação de empreendedorismo individual, porque uma única pessoa desempenha todas as funções dos processos de produção e comercialização dos alimentos: pães de mel, alfajores e tortas.

Individualmente, portanto, são providenciados os insumos para a produção e para o acondicionamento dos alimentos nas embalagens, além do desenvolvimento da própria produção e da oferta dos produtos diretamente aos consumidores.

Atualmente, alguns aspectos do negócio estão em processo de profissionalização. Assim, o empreendimento conta como uma cozinha industrial e como uma tabela nutricional dos produtos, que foi elaborada por profissional especializado. Outros aspectos, no entanto, ainda se mostram incipientes, como o cadastro de clientes e o processo de compra de insumos alimentícios.

Do ponto de vista deste trabalho, os aspectos diretamente considerados no avanço do processo de profissionalização do negócio são relativos à comunicação visual da marca e ao planejamento, à organização e à supervisão do trabalho de impressão das embalagens para os produtos serem oferecidos aos consumidores. 0 objetivo geral, para a ação de Design Gráfico, com base nos estudos exploratórios realizados, foi projetar a identidade visual e produtos de comunicação gráfica da marca RosaMel, de acordo com as indicações propostas pela abordagem de Gestão de Design.

De acordo com as indicações da empreendedora e do que foi possível observar diretamente, durante o trabalho realizado, há uma boa aceitação dos produtos da marca RosaMel. Isso é considerado de acordo com a organização e a capacidade produtiva do negócio, que se caracteriza como empreendimento individual. A aceitabilidade e a procura constantes indicam seu potencial de crescimento ainda como empreendimento individual. Considera-se, entretanto, que o crescimento depende da finalização e da consolidação do processo de profissionalização, pois depende de processos bem formalizados, até para permitir a inclusão de outros trabalhadores no processo.

Este artigo apresenta um relatório de mais uma etapa de profissionalização do empreendimento individual em estudo. Primeiramente, considerando-se que Gestão de 


\section{COMUNICAÇÃO GRÁFICA DA MARCA ROSAMEL: UM ESTUDO DESCRITIVO-INTERPRETATIVO}

Design, entre outras possibilidades, prevê a contribuição participativa dos designers no processo integral de gestão, para propor soluções ou incrementos ao empreendimento, de acordo com sua área de atuação. Assim, foram desenvolvidas as potencialidades da área de Design, no processo de profissionalização da comunicação gráfica da marca RosaMel.

Isso caracteriza o esforço e também a possibilidade de profissionalização de serviços, processos produtivos e produtos em pequenos negócios, especialmente os bem sucedidos, preparando-os para o crescimento formalizado. Isso reduz as limitações ou impedimentos decorrentes das soluções puramente intuitivas, que são comumente adotadas na manutenção dos pequenos negócios.

\subsection{Empreendedorismo Individual no Brasil}

No âmbito dos negócios oficializados e acessíveis por meio da Agência Sebrae (2011), no mês de julho de 2011, foram contabilizados 1,5 milhão empreendedores individuais registrados. Entre esses, 44.000 eram registrados em Santa Catarina, sendo que $87 \%$ desses não apresentam nenhum registro de empregados e $60 \%$ não dispõem sequer da ajuda de familiares, apesar dessa ser a única fonte de renda para $78 \%$ dos empreendedores registrados.

Há cerca de cinco anos, houve a criação da figura jurídica do Micro Empreendedor Individual (MEI), através da Lei complementar 128/2008, considerando-se artigos da Constituição Federal, como uma tentativa de incluir na formalidade, os empreendedores de mais de 300 segmentos de negócios. Para tanto, foram oferecidos benefícios que vão desde a possibilidade de emissão de nota fiscal até facilitações para empréstimos, oportunizando a qualificação profissional e o crescimento dos pequenos negócios.

Houve um incremento na arrecadação e a regulamentação do processo social que, em parte, justificaram o interesse e a iniciativa do governo, apesar de ainda não ser perceptível uma mudança significativa no mercado em decorrência dessa medida. A economia como um todo é configurada por negócios formais e informais, sejam grandes ou pequenos. Porém, o mercado consumidor exige cada vez mais garantias e requer a formalização dos negócios e da produção como expressão perceptível da qualidade dos produtos e serviços que thes são oferecidos.

A qualidade é percebida diretamente no produto ou no serviço, mas a é a qualidade dos processos de gestão e de produção que definem a qualidade dos bens produzidos. Além disso, geralmente, a publicidade formal ou informal antecede a venda do produto ou serviços, portanto, a imagem de marca, sua reputação, é um bem necessário para a manutenção e crescimento de qualquer negócio. Isso justifica as mais diversificadas estratégias e ações de branding. A identidade visual da marca impressa nas embalagens ou nos produtos, bem como a própria aparência e qualidade das instalações de venda, dos meios de transporte, dos uniformes dos colaboradores e, especialmente das embalagens caracterizam um tipo de publicidade que antecede imediatamente ao produto, influenciando de imediato a decisão de compra do consumidor. 


\section{COMUNICAÇÃO GRÁFICA DA MARCA ROSAMEL: UM ESTUDO DESCRITIVO-INTERPRETATIVO}

Essas considerações são válidas para o mercado como um todo, sendo recorrentes em livros das áreas de Gestão de Marketing (KOTLER e KELLER, 2006), de Branding (MARTINS, 2006) ou de Identidade Visual da Marca (WHEELER, 2008). São igualmente válidas, portanto, para os pequenos negócios de empreendedores individuais.

A área de Gestão de Design busca conhecer e participar do amplo contexto da gestão de negócios, visando à ação positiva do designer nas estratégias e ações empreendedoras. Assim, a área de Design pode e deve oferecer soluções necessárias aos empreendimentos individuais e, juntamente com outros aspectos relacionados à profissionalização do negócio, pode colaborar para a manutenção qualificada e para o crescimento dos pequenos negócios.

\subsection{Design e Profissionalização de Processos Produtivos.}

A informalidade legal ainda caracteriza parte dos empreendimentos individuais, mesmo depois do esforço de formalização que configurou juridicamente o Micro Empreendedor Individual (MEI). Entretanto, além da informalidade legal, também, existe a informalidade profissional, pois, há empreendedores individuais que não adquiriram o conhecimento dos processos de profissionalização, mesmo havendo informações disponíveis na internet e em outras fontes.

Além de participar da ampla avaliação do processo produtivo, indicar fontes de informações e profissionais que auxiliem na profissionalização do negócio, o designer deve atuar pontualmente no planejamento e desenvolvimento de produtos e soluções diretamente relacionadas ao seu campo de atividades.

No tocante aos produtos gráficos, o designer dispõe de conhecimentos específicos para prospectar necessidades e características, projetar e acompanhar o desenvolvimento de produtos de comunicação, inclusive, rótulos e embalagens, entre outros. Assim, além de projetar a identidade visual do empreendimento é possível também projetar o conjunto de produtos, como rótulos, etiquetas, folhetos, embalagens e websites ou páginas na internet que comunicam a identidade da marca e fazem referência às especificações técnicas ou jurídicas, além de salientar as qualidades sensíveis dos produtos ou serviços.

Para tanto, a percepção do designer deve ser integrada e estar a serviço da filosofia geral do negócio, atuando como consultor e parcialmente como gestor e articulador de processos. As etapas são as seguintes: (1) conhecimento teórico-prático; (2) reconhecimento da situação; (3) envolvimento com a realidade do negócio; (4) projetação e supervisão do desenvolvimento de produtos voltados para a profissionalização do empreendimento.

As etapas e os resultados caracterizam um estudo com (1) uma fase exploratória e (2) outra qualitativo-descritiva e participante, cuja finalidade é compor uma pesquisa aplicada à solução de problemas com relação à profissionalização de empreendimentos individuais. Os recursos utilizados são: (1) observação sistemática; (2) entrevistas semi-estruturadas, e (3) metodologia de projetos de design. 


\section{COMUNICAÇÃO GRÁFICA DA MARCA ROSAMEL: \\ UM ESTUDO DESCRITIVO-INTERPRETATIVO}

As etapas e os estudos indicados neste item foram desenvolvidos durante o percurso em que se aplicaram conhecimentos e atividades relacionadas às áreas de Gestão de Design e Design Gráfico, na continuidade do processo de profissionalização do empreendimento individual sob a marca RosaMel.

\section{Design, Gestão de Design e Identidade Visual}

\subsection{Design e Design Gráfico}

Devido à variedade de enfoques e recortes, há dificuldades em conceituar e o campo de estudos e atividades de Design e definir seu objeto de estudos em Design. Todavia, considera-se que o termo "Design" caracteriza um conjunto de atividades lógico-projetivas desenvolvidas a partir de um método, visando representar a solução formal ou ideal para um determinado produto. Assim, a informação é o produto imediato do campo de Design, que projeta processos e produtos como solução de problemas pré-determinados.

Em uma pesquisa realizada a partir dos trabalhos de conclusão do curso (TCC) de Design Gráfico da Universidade Federal de Santa Catarina, no período entre os anos de 2005 e 2010 (PERASSI e REGINALD0, 2011), foram resgatadas as ideias e conceituações de autores e publicações mais recorrentes nas referências dos trabalhos pesquisados. As publicações e os autores considerados foram os seguintes: Azevedo (1998); Bonsiepe (1997); Bürdek (2006); Escorel (2000); Frascara (2000); Fuentes (2006); Löbach (2001), e Villas Boas (2003). A síntese do resgate teórico realizado é o seguinte texto:

\footnotetext{
“Design gráfico é a atividade intencional de projetação do produto gráfico, usando linguagem específica, para orientar a expressão da forma ou ideia, impressa ou digital, sobre o suporte planejado, configurando todo o conjunto como informação ou mensagem, de acordo com seu significado no contexto em que está inserido. 0 objetivo expresso é constituir uma interface informativa eficiente, que permita a comunicação entre o emissor e o receptor. Assim, para cumprir essa finalidade, o designer, como profissional responsável, deve planejar ou realizar diversas atividades de preparação e supervisão do processo de desenvolvimento do projeto, até a entrega do produto gráfico (PERASSI, 2001, p. 16)."
}

A ideia proposta acima pode ser reduzida e generalizada para conceituar Design de maneira geral como: "atividade intencional de projetação", "usando linguagem específica" para expressar ideias, como informação prático-funcional ou simbólico-comunicativa. 0 objetivo é constituir interfaces eficientes, como soluções para problemas previstos. 0 designer deve planejar e realizar diversas atividades de preparação e supervisão do processo, desde a fase inicial de planejamento até a entrega do produto projetado.

As atividades propostas acima podem não esgotar todas as possibilidades e responsabilidades em Design, porém, configuram a conceituação adotada no desenvolvimento desta pesquisa aplicada, na qual foram também considerados os princípios de Gestão 


\section{COMUNICAÇÃO GRÁFICA DA MARCA ROSAMEL: \\ UM ESTUDO DESCRITIVO-INTERPRETATIVO}

de Design. Esses princípios propõem o relacionamento, através da interação direta entre o gestor de Design e a equipe de gestão da organização, em torno da prospecção de necessidades, planejamento de estratégias e de ações, visando soluções organizacionais ou mercadológicas, entre outras, que são decorrentes das atividades de Design.

A origem do campo de Design é relacionada ao contexto de formação da sociedade industrial. Desde o início o campo de estudos e atividades em Design manifesta um forte sentido moral, visando a solução de problemas e a melhoria das condições de vida em sociedade. Porém, neste país, esse campo surgiu como área de conhecimento em 1962, com a fundação da Escola Superior de Desenho Industrial (ESDI) na cidade Rio de Janeiro.

A expressão "desenho industrial" demarcou o vínculo de origem entre Design e produção industrial, sob a máxima bauhausiana "a forma segue a função". Para Dorfles (1963) um objeto é caracterizado como produto de Desenho Industrial por: (1) sua fabricação em série; (2) sua produção mecânica; (3) sua projetação, que prevê sua configuração. Portanto, o desenho industrial é decorrência da cultura industrial, não havendo similares em culturas anteriores.

Atualmente, entretanto, o termo Design foi adotado por diferentes entidades como: International Council of Graphic Design Associations (ICOGRADA); International Council of Societies of Industrial Design (ICSID). 0 governo brasileiro, através do Projeto de Lei nć 1.965, também adotou o termo "Design", que é utilizado pelo Instituto Brasileiro de Geografia e Estatística (IBGE) e pelo Ministério da Educação e Cultura (MEC) e, ainda, pela Associação Brasileira de Empresas de Design (ABEDesign), entre outros.

A denominação Design, além de continuar associada à produção industrial de larga escala, também, prevê projetos e produtos adaptados para diferentes tecnologias e demandas específicas. Isso justifica a expressão Design Social, incluindo adaptações personalizadas, porque a tecnologia digital permite a customização de produtos industrializados para atender demandas individualizadas.

Gui Bonsiepe (2011) enfatiza o caráter projetual de Design. Pois, enquanto as ciências percebem o mundo sob a perspectiva da cognição, Design atua sob a perspectiva do projeto. Em Design Gráfico, especificamente, o projeto desencadeia um processo técnico e criativo que utiliza imagens e textos para comunicar mensagens, idéias e conceitos, com objetivos comerciais ou de fundo social.

Além de diversos produtos de comunicação visual, a área de Design Gráfico é tradicionalmente responsável pelo projeto de "Identidade Visual Corporativa" dos diferentes tipos de organização e, também, de identidade gráfico-visual de produtos e serviços (PEÓN, 2003).

\subsection{Gestão de Design}

Design estabelece uma relação interativa e pró-ativa com outros campos de atividades, influenciando ou determinando o processo de gestão das organizações, através de atuação prescritiva (MOZOTA, 2011). 


\section{COMUNICAÇÃO GRÁFICA DA MARCA ROSAMEL: UM ESTUDO DESCRITIVO-INTERPRETATIVO}

Gimeno (2000) identifica nas empresas a possibilidade de utilização de Design em 5 níveis: (1) Projeto de Design; (2) Programa de Design; (3) Política de Design; (4) Estratégia de Design; (5) Filosofia de Design.

Quando está restrito à área fim, tradicionalmente, o designer atua de modo operacional, atendendo a solicitações prévias e específicas. Porém, dentro de uma visão estratégica, na qual as finalidades são decorrentes de processos integrados de planejamento e desenvolvimento, o designer deve sempre contribuir e, às vezes, coordenar as decisões estratégicas, que serão atendidas por meio de projetos de design.

Mozota (2011) enfatiza que, nesses casos, os designers auxiliam na conceituação dos valores organizacionais e, assim, trabalham no processo de ideação da empresa. Isso significa que os designers devem assumir seu papel na equipe de liderança das organizações.

0 designer é envolvido, portanto, no processo de planejamento e no processo produtivo. Assim, as atividades de Design podem servir para o planejamento, como "design para racionalização", ou como processo de produção, definindo o "design para a diferenciação". O livro "A Estratégia do Oceano Azul" (CHAN KIM e MAUBORGNE, 2005) apresenta os exemplos bem sucedidos do "Circo de Soleil" e da rede de academias Contours, na área de serviços, e, também do vinho australiano Yellow Tail, na área de produtos, ilustrando as possibilidades do design nas estratégias de negócios.

Entre as atividades características da área de Design Gráfico, destaca-se o projeto de identidade visual corporativa, como projeto de diferenciação, desenvolvido a partir de um amplo processo de planejamento ou racionalização.

\subsection{Identidade Visual da Marca}

Para Strunck (2007, p. 18), na visão da identidade gráfico-visual, “a marca é um nome, normalmente representado por um desenho". É denominado "logotipo" o desenho que se caracteriza como o modo específico de escrever o nome. Porém, quando há uma figura associada ao logotipo, esse outro desenho é denominado de "símbolo" gráfico. Porém, "devido às experiências reais ou virtuais, objetivas ou subjetivas", que o público relaciona à marca ao longo do tempo, o conjunto gráfico passa a ser percebido como "um valor específico."

Nos primórdios da economia de mercado, os consumidores solicitavam o tipo de produto de que necessitavam ao balconista, que sugeria a marca mais adequada. Nesta sociedade da informação e do hiper-consumo, a marca se comunica diretamente com 0 público consumidor, enquanto disputa atenção e espaço com várias outras.

De acordo com Perassi (2005) há itens necessários à comunicação eficiente da marca gráfico-visual, tais como: (1) visibilidade, (2) atratividade, (3) competitividade, (4) comunicabilidade, (5) reprodutibilidade, (6) versatilidade e (7) bom acabamento.

A mensagem transmitida durante a percepção dos elementos componentes da identidade visual corporativa, especialmente na configuração da marca gráfica, é uma promessa 


\section{COMUNICAÇÃO GRÁFICA DA MARCA ROSAMEL: UM ESTUDO DESCRITIVO-INTERPRETATIVO}

de atributos e valores, para o produto ou serviço que representa. Por isso, a marca gráfica e os outros elementos da identidade visual devem expressar coerência com os valores organizacionais e, também, unidade consistente, nas diferentes situações em que são expostas ou emitidas à percepção pública.

Isso diz respeito aos diversos formatos da mensagem gráfica, tendo em vista seus diferentes meios de transmissão ou de suporte. Portanto, cabe ao designer desenvolver projetos gráficos, considerando a necessidade de gestão da mídia gráfica e da comunicação visual. Entre esses, destacam-se, por exemplo, os uniformes e o tratamento visual dos equipamentos na área de serviços e as embalagens na área de produtos. As embalagens são suportes privilegiados da identidade visual da marca e canais de contato direto entre seus elementos gráficos e o público consumidor.

\subsection{Design de Embalagens}

A embalagem é um produto associado ao produto embalado, cuja função principal é proteger esse último. Porém, ao longo do tempo a embalagem foi sendo sofisticada, como interface mediadora da comunicação da marca com o público consumidor. Muitas vezes, a embalagem não só protege o produto, como também o apresenta ao público, seja diretamente, por meio de materiais transparentes, ou indiretamente, através de imagens impressas em sua superfície. Em praticamente todos os casos, as embalagens expressam elementos gráfico-visuais, os quais atuam como identificadores da marca.

A embalagem é um relevante ponto de contato do público com a marca, sendo necessário o cuidado com essa comunicação, especialmente, em situações onde não há um ponto de venda próprio ou não se dispõe de verba para outras ações de publicidade e propaganda. Assim, a embalagem assume outras funções além de servir para acondicionamento, transporte e proteção dos produtos. Mestriner (2002) assinala que a embalagem é suporte privilegiado de informação do produto.

0 design de embalagens prevê a possibilidade de planejamento de um sistema de embalagens para um produto ou linha de produtos. Muitas vezes, serve de suporte para o reposicionamento da marca e do produto, partindo-se da revisão das embalagens já existentes, tendo em vista a comunicação publicitária, mas também a identificação da marca e a comunicação técnica e jurídica, como elementos que oferecem credibilidade e legalidade aos produtos.

Ao criar uma nova embalagem ou sistema de embalagens é necessário investigar e levar em consideração as normas específicas do segmento e do mercado de inserção do produto. Entre outras, as embalagens de brinquedos infantis, requerem impressão de avisos específicos. Embalagens alimentícias e farmacêuticas são regulamentadas por normas específicas de rotulagem e de uso de materiais. É igualmente necessária a avaliação do ciclo de vida da embalagem projetada, buscando atender as necessidades do cliente e as do público-consumidor e minimizando os impactos ambientais. 


\section{COMUNICAÇÃO GRÁFICA DA MARCA ROSAMEL: \\ UM ESTUDO DESCRITIVO-INTERPRETATIVO}

\section{Materiais e Métodos}

\subsection{Caracterização da Pesquisa}

A pesquisa relatada neste artigo teve início a partir de estudos exploratórios. Entre outros dados, foi identificado o uso recorrente de alguns elementos gráficos em diferentes situações de comunicação. Mas, sem o estabelecimento coerente de uma identidade gráfico-visual. Segundo Péon (2003), essa identidade requer clareza, uniformidade e recorrência na definição de elementos, como identificadores gráfico-visuais da marca.

Foi evidenciado o desconhecimento sobre a realidade da marca no mercado. Isso caracterizou o problema de pesquisa, porque impedia a avaliação da situação e dificultava o planejamento da comunicação gráfica da marca. Foi realizada, portanto, uma pesquisa de campo junto à cliente-emissora e alguns consumidores da marca para o reconhecimento dos princípios de identidade e da imagem da marca.

Durante o processo de pesquisa, procurou-se (1) identificar as características da produção e dos produtos "RosaMel" e o modo de percepção dos consumidores; (2) reunir recursos teórico-práticos para o reconhecimento da marca e do seu processo de comunicação; (3) compor um panorama geral da atuação da marca que viabilize o trabalho de projetação; (4) desenvolver o projeto de identidade visual e de sua aplicação nos produtos de comunicação da marca.

Conforme a classificação de Lakatos e Marconi (1991) a pesquisa realizada se caracteriza como a parte preparatória para uma "pesquisa aplicada", porque visou a reunião de dados teóricos e práticos, para o futuro desenvolvimento de um projeto de revisão da identidade visual da marca RosaMel e sua aplicação em produtos de comunicação.

Para obtenção dos dados foram desenvolvidos estudos exploratórios, estudos teóricos e, ainda, uma pesquisa de campo. A pesquisa de campo foi desenvolvida por meio de observação sistemática da realidade e realização de entrevistas sob uma abordagem descritiva, de cunho interpretativo-qualitativo e base fenomenológica. A pesquisa descritiva é desenvolvida, por meio da percepção e descoberta, procurando compreender um determinado evento, sendo adequada para compreender-se o fenômeno estudado, sob a perspectiva dos informantes e não dos pesquisadores ou das teorias existentes.

\subsection{0s Dados Observados}

Os estudos exploratórios e a pesquisa de campo permitiram o levantamento da composição dos produtos alimentícios oferecidos ao mercado sob a marca "RosaMel" (Tabela 1). Esses produtos são: bolos, mini-bolos, tortinhas, pães de mel, alfajores, e trufas. Exceto os bolos e as tortinhas, todos os outros produtos apresentam a substância mel natural de abelha, como parte de sua composição. Assim, o nome da marca apresenta a palavra "mel" e o sabor da substância mel aparece na maioria dos seus produtos, sendo igualmente expressão da marca. Isso promove a ideia de que, para o conhecimento e a comunicação da marca, seria interessante que fosse introduzida a substância mel 


\section{COMUNICAÇÃO GRÁFICA DA MARCA ROSAMEL: \\ UM ESTUDO DESCRITIVO-INTERPRETATIVO}

na composição de todos os produtos da marca.

Tabela 1: Produtos da empresa RosaMel

\begin{tabular}{|c|c|c|}
\hline Produto & Tipos / Variedades & Distribuição ao Cliente \\
\hline Bolo & $\begin{array}{l}\text { - sabores: coco; chocolate, e } \\
\text { chocolate com coco e casta- } \\
\text { nha. } \\
\text { - produto vendido por quilo }\end{array}$ & $\begin{array}{l}\text { - pedidos por telefone e sob enco- } \\
\text { menda }\end{array}$ \\
\hline Tortinhas & $\begin{array}{l}\text { - sabores: coco, chocolate e } \\
\text { chocolate c/ coco e castanha. } \\
\text { - porções individuais }\end{array}$ & $\begin{array}{l}\text { - pedidos por telefone e sob enco- } \\
\text { menda }\end{array}$ \\
\hline Pão de Mel & $\begin{array}{l}\text { - cobertura de chocolate bran- } \\
\text { co ou ao leite } \\
\text { - em cubos pequenos (vendi- } \\
\text { do por quilo) } \\
\text { - ou quadrado (porção indivi- } \\
\text { dual) } \\
\text { - com ou sem glúten }\end{array}$ & $\begin{array}{l}\text { - pedidos por telefone e sob enco- } \\
\text { menda } \\
\text { - representante comercial }\end{array}$ \\
\hline Alfajores & $\begin{array}{l}\text { - cobertura de chocolate bran- } \\
\text { co ou ao leite } \\
\text { - formato redondo (porção } \\
\text { individual) }\end{array}$ & $\begin{array}{l}\text { - pedidos por telefone e sob enco- } \\
\text { menda } \\
\text { - representante comercial }\end{array}$ \\
\hline $\begin{array}{l}\text { Minibolo de } \\
\text { Pão de Mel } \\
\text { Recheado } \\
\end{array}$ & $\begin{array}{l}\text { - recheio com castanha, uva } \\
\text { passa e chocolate ao leite } \\
\text { - porção individual (150gr) }\end{array}$ & $\begin{array}{l}\text { - pedidos por telefone e sob enco- } \\
\text { menda } \\
\text { - representante comercial }\end{array}$ \\
\hline $\begin{array}{l}\text { Trufa de Pão } \\
\text { de Mel }\end{array}$ & - porção individual & $\begin{array}{l}\text { - pedidos por telefone e sob enco- } \\
\text { menda } \\
\text { - representante comercial }\end{array}$ \\
\hline
\end{tabular}

Foi possível também observar o acondicionamento dos produtos, reconhecendo a maneira como esses são apresentados ao público consumidor.

De maneira geral, são utilizadas embalagens plásticas compradas por atacado para conter e proteger os produtos. A identificação da marca decorre da impressão de elementos gráficos sobre partes da própria embalagem ou sobre etiqueta (Fig. 1e 2) afixada sobre as embalagens. 


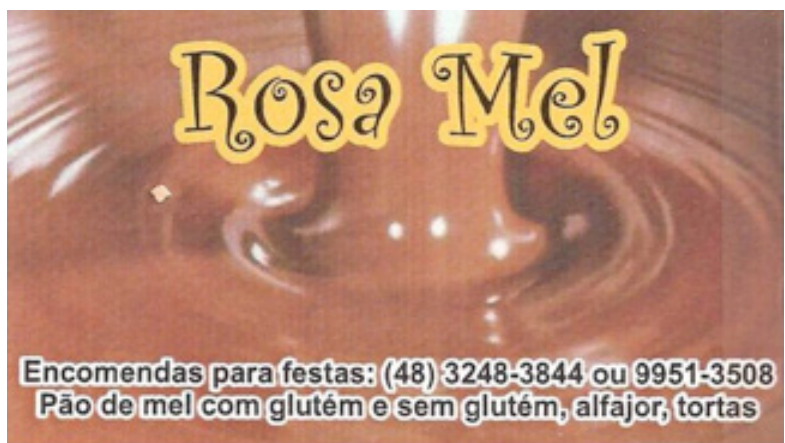

Fig. 1: Etiqueta que é afixada nos produtos RosaMel. Fonte: RosaMel.

Os produtos como bolos e tortinhas são entregues em embalagem de plástico rígido compostas de uma base opaca em formato de prato e de uma tampa transparente, que permite a visualização do produto. Sobre a tampa há uma etiqueta impressa com o nome da marca e com o número do telefone para encomendas, entre outros elementos gráficos.

Os produtos "trufas de pão de mel" são embalados como bombons, em papéis coloridos diversos, sem identificar a marca ou o tipo de produto (Fig. 2).

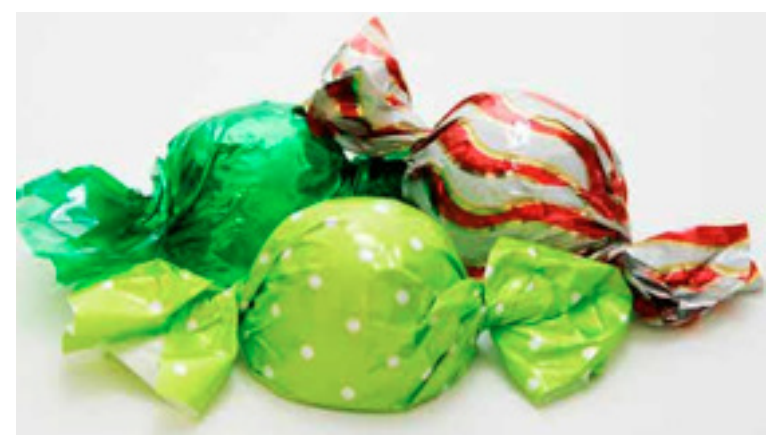

Fig. 2: Embalagens de trufas RosaMel. Fonte: RosaMel.

Os produtos como alfajores; "mini-bolos de pão de mel”, e pães de mel são embalados em pequenos sacos plásticos transparentes flexíveis. Algumas embalagens desse tipo são estampadas com figuras de abelhas ou outros motivos (Fig. 3). 


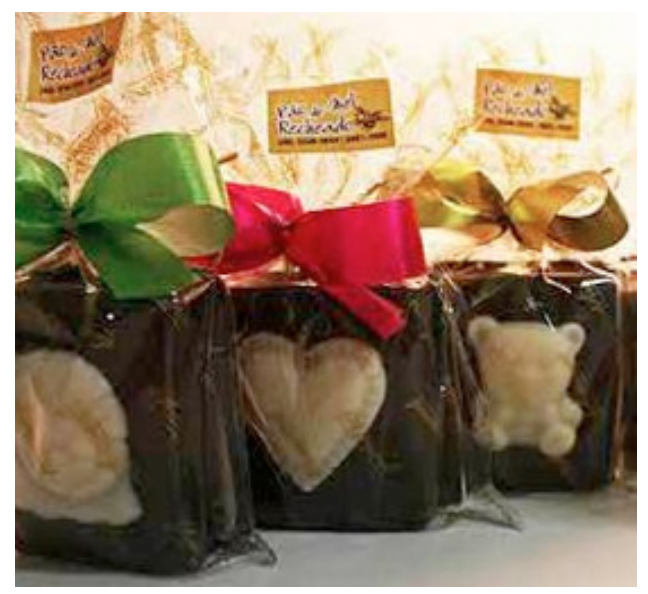

Fig. 3: Embalagens de pães de mel RosaMel. Fonte: RosaMel.

Sobre essas embalagens, também, são afixadas etiquetas (Fig. 4), com o nome do produto e da marca e o telefone para contato.

Os produtos que não contém glúten em sua composição, também, são identificados, com a expressão "sem glúten" impressa em uma tarja vermelha sobre a etiqueta de identificação (Fig. 4).

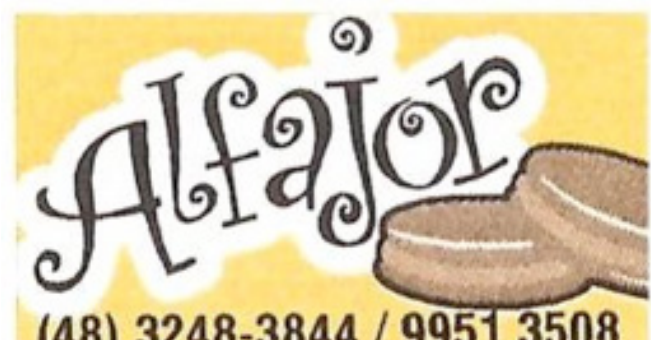

(48) $3248-3844 / 99513508$

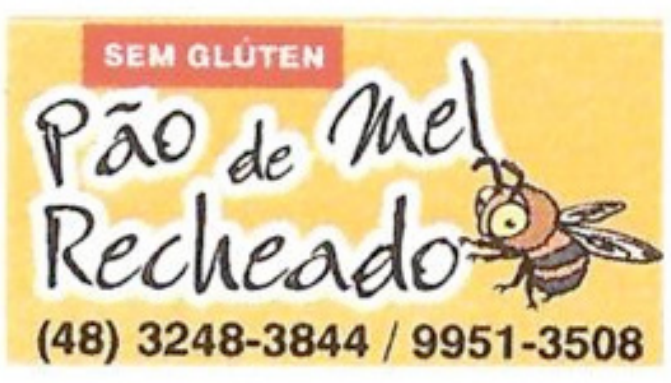

Figura 4: Etiquetas específicas que são afixadas nos produtos RosaMel. Fonte: RosaMel.

Em datas especiais, como Natal e Páscoa, a empreendedora oferece embalagens temáticas de materiais e tipos diversos (Fig. 5). Em algumas delas é possível agregar a etiqueta com identificação da marca e/ou produto. 


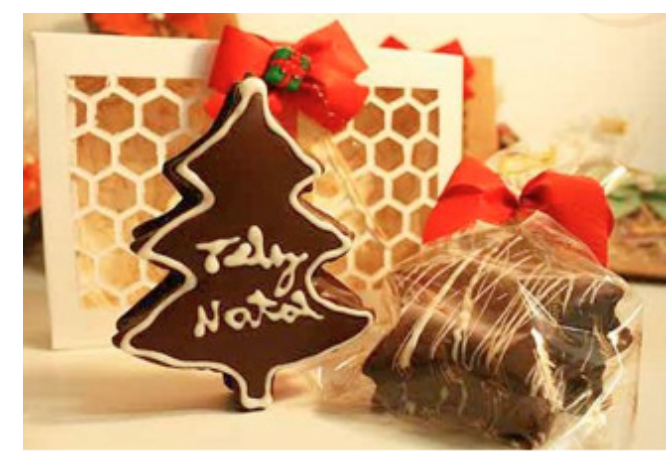

Fig. 5: Produtos e embalagens temáticas RosaMel. Fonte: RosaMel.

0 cartão de visitas e as etiquetas atuam como indicativos de contato, com número de telefone e endereço eletrônico do website da marca. 0 próprio website da marca na internet também atua como cartão de visitas e folder, multimídia, dinâmico e interativo (Fig. 6).

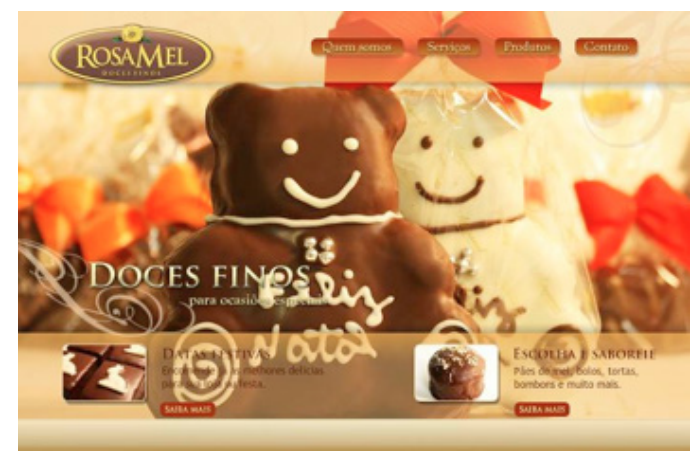

Figura 6: Página inicial do sítio digital RosaMel. Fonte: RosaMel.

\subsection{Pesquisa de campo.}

No processo de pesquisa de campo, além das entrevistas com a empreendedora proprietária do negócio e da marca, foram realizadas entrevistas semi-estruturadas com clientes consumidores de seus produtos.

A pesquisa com clientes da marca foi feita a partir de uma amostragem fornecida pela própria empreendedora, porque ainda não há um cadastro de clientes da marca devidamente organizado e atualizado, que possa oferecer outros recursos de contato além dos números de telefone.

Houve 11 contatos propostos e quatro questionários efetivamente respondidos. As perguntas realizadas para serem respondidas de forma aberta foram as seguintes: (1) Como conheceu a marca RosaMel? (2) Que produtos a marca RosaMel costuma oferecer? (3) Quando foi sua primeira compra? (4) Quando comprou seus produtos pela última 


\section{COMUNICAÇÃO GRÁFICA DA MARCA ROSAMEL: UM ESTUDO DESCRITIVO-INTERPRETATIVO}

vez? (5) Quais os motivos que justificam suas compras? Qual a imagem que se faz dos produtos, são doces artesanais finos e sofisticados ou artesanais simples e criativos?

Dois entrevistados informaram que tomaram contato com a marca através de indicação de amigos e os outros dois conheceram a marca diretamente em pequenos distribuidores, os quais também comercializavam outros tipos de produtos alimentícios.

Dois entre os entrevistados se declararam clientes constantes dos produtos da marca e outros dois indicaram sazonalidade nas compras, distribuídas em datas distantes, demarcando festas como aniversários ou Natal. Porém, todos responderam que conhecem a marca há, pelo menos, mais de cinco anos.

Os valores indicados como responsáveis pela preferência foram todos referentes aos produtos ou ao seu modo de apresentação. Foi destacado o caráter artesanal predominando sobre sofisticação ou outros atributos que pudessem ser associados à expressão "doces finos".

Os produtos foram considerados artesanais, muito saborosos e de boa apresentação, sugerindo também cuidado e higiene, por isso, inspiram confiança. Outro atributo positivo que foi destacado é a criatividade na apresentação e na variação de formatos em situações comemorativas especiais. Sobre isso foi dito: "sempre traz novidades, coisinhas diferentes... que fazem ficar especial".

Apesar de reconhecerem os produtos, sua qualidade e valores, a imagem desses não foram associados à memória do nome da marca "RosaMel" ou a outros símbolos relacionados à marca, como as imagens de abelhas nas embalagens. Os entrevistados que compram por encomendam diretamente da empreendedora, associam os produtos mais a imagem da proprietária do que da marca gráfica que os identifica.

\section{Interpretação dos Dados}

Diante do observado e dos dados coletados na pesquisa de campo, considera-se que, de modo geral, há indefinição no processo de comunicação da marca. Isso também sugere indeterminação no posicionamento do negócio, com relação ao mercado em geral e ao público-consumidor especificamente.

Primeiramente, é possível observar nas imagens apresentadas anteriormente (Fig. 1, 2, $3,4,5,6)$ que há uma ampla variação no modo de apresentação da marca.

No website da marca na internet (Fig. 6), dominam das cores marrom, bege e a alta qualidade gráfica da composição das páginas e das imagens dos produtos que receberam tratamento de luz e são compostas com fundos limpos e cortes profissionais. Isso sugere alta qualidade profissional e sofisticação de produtos e embalagens. 0 sentido de sofisticação é reforçado pelo emblema proposto no website, como marca gráfica RosaMel. (Fig. 7). 


\section{COMUNICAÇÃO GRÁFICA DA MARCA ROSAMEL: \\ UM ESTUDO DESCRITIVO-INTERPRETATIVO}

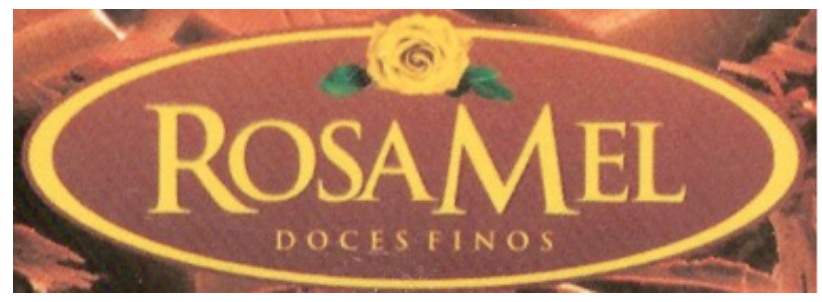

Fig. 7: Página inicial do website digital RosaMel. Fonte: RosaMel.

0 emblema (Fig. 7) é contornado por uma elipse em cor amarela. Na parte central superior, é mostrada a imagem de uma rosa amarela, com folhas verdes. Sob a imagem da rosa, aparece o nome "ROSAMEL" com tipografia em caixa alta com serifa, de tamanho variado e cor amarela. Sob o nome, em tamanho menor, aparece a expressão "DOCES FINOS", também e caixa alta e cor amarela. 0 conjunto composto por imagem e palavras aparece sobre um fundo na cor marrom, com leve variação de tonal.

A composição visual-gráfica do website, especialmente, do emblema descrito acima (Fig. 7) é diferente da composição visual do cartão de visitas (Fig. 1) e das etiquetas (Fig. 4). Foram identificadas marcas gráficas distintas. No cartão de visitas (Fig. 1), por exemplo, o logotipo da marca gráfica é apresentado em tipos pretos decorativos sobre um fundo amarelo recortado como um contorno largo das letras.

$\mathrm{Na}$ entrevista com a empreendedora, foi informado que cada uma das marcas foi criada em uma situação diferente, para atender necessidades de um momento específico. Além disso, não foi possível identificar se o desenho da abelha que aparece em alguns produtos gráficos é reconhecido como símbolo da marca. Os clientes entrevistados não se lembraram desse elemento visual e o emblema do website propõe outro símbolo que é a rosa amarela. 0 nome "RosaMel" foi escolhido pela empreendedora com a ajuda de parceiros e familiares, quando teve início a comercialização dos produtos. 0 nome relaciona o nome da empreendedora, "Rosa", com a substância "mel", que caracteriza a maioria dos produtos.

Com relação aos tipos gráficos, foram encontradas seis diferentes tipografias nos produtos gráficos pesquisados. Há tipos "Arial" e "Times New Roman", mas há ainda outras quatro tipografias, sendo que três remetem à escrita manual, com gestual leve. 0 logotipo no emblema do website, em caixa alta e com serifas finas, que lembram a tipografia "Coluna de Trajano", remetendo ao estilo clássico.

\section{Considerações Finais}

Este artigo relata uma pesquisa descritiva, que se apresenta como estudo de caso da marca "RosaMel", identificando um negócio do setor de produtos alimentícios artesanais, tais como: pães de mel, bolos e alfajores, entre outros. Os produtos são oferecidos em diferentes formatos ou quantidades e embalados de maneiras diversas, inclusive, seguindo a temática de festividades específicas, como a festa de Natal. 


\section{COMUNICAÇÃO GRÁFICA DA MARCA ROSAMEL: \\ UM ESTUDO DESCRITIVO-INTERPRETATIVO}

Considera-se que o que foi encontrado nesta pesquisa retrata as circunstâncias de diversos pequenos negócios brasileiros, que tratam de produtos similares. A pesquisa evidencia a necessidade da gestão do design em pequenos negócios, que pode ser desenvolvida por designers, para indicar e qualificar a necessidade de projetos que profissionalizem o empreendimento.

No contexto de Branding ou Gestão da Marca, a área de Design Gráfico foi privilegiada neste estudo, evidenciando a necessidade de definição dos valores da marca e dos seus elementos de identificação gráfico-visual, promovendo o estabelecimento, de maneira recorrente, do posicionamento da marca no mercado e da efetivação da imagem positiva da marca nas mentes do público consumidor.

Convivendo-se diretamente com os produtos é possível perceber a qualidade dos mesmos que, também, é reconhecida e prestigiada pelos clientes entrevistados. A "criatividade" é um atributo apontado positivamente, caracterizando a diversidade de modos de apresentação dos produtos, especialmente em ocasiões especiais. Tal fato, no entendo, dificulta que a marca seja estabelecida, por exemplo, pela recorrência das embalagens. Assim, falta de recorrência é percebida nas embalagens e, também, nas diferentes versões gráficas dos logotipos da marca e dos produtos visuais, como o cartão de visitas, as etiquetas e a apresentação gráfica do website da marca.

Na perspectiva teórica da área de Cestão de Design, orientando a prática da gestão do design, percebe-se a necessidade de definição do posicionamento da marca no mercado e na mente do público consumidor.

0 website da marca na internet é graficamente bem produzido e propõe a marca "RosaMel", como símbolo identificador da produção artesanal de "doces finos" (Fig. 6 e 7). Para tanto, apresenta os elementos gráfico-visuais da marca associados a um estilo clássico e sofisticado (Fig. 7). Todavia, é diferente a percepção dos clientes-consumidores dos produtos da marca, cujos valores indicados aos produtos são relacionados ao sabor, à higiene e ao caráter artesanal-caseiro, que inspira confiança, mas sem sugerir sofisticação. 0 posicionamento artesanal-caseiro é expresso também em etiquetas, embalagens e nos próprios produtos (Fig. 4 e 5).

0 conjunto da produção, fora do website, não se mostra coerente com o slogan ou a tagline da marca, que apresenta a expressão "doces finos". Caso seja desejável manter esse posicionamento, torna-se necessário a revisão das expressões da marca, considerando-se tanto a apresentação dos produtos, quanto as embalagens e outros produtos gráficos, excetuando-se apenas a composição gráfica do website da marca.

Para se estabelecer o posicionamento indicado como "artesanal-caseiro", que se mostra mais coerente com a apresentação dos produtos e com a "criatividade" ou variedade e adaptabilidade das embalagens, também, são necessárias revisões. Para começar, é necessário um projeto de identidade visual da marca para se construir padrões de recorrência, mesmo com a manutenção do atributo "criatividade" ou variedade. É necessário, portanto, a busca de unidade visual nos produtos gráficos de comunicação, como etiquetas, cartão de visita e outros, incluindo-se a revisão do emblema gráfico do sítio da marca na internet.

É interessante para a consolidação da marca, que o nome "RosaMel" seja a principal 


\section{COMUNICAÇÃO GRÁFICA DA MARCA ROSAMEL: \\ UM ESTUDO DESCRITIVO-INTERPRETATIVO}

referência dos produtos. Para tanto, faz-se necessário que o nome seja constantemente expresso, em um mesmo formato gráfico-visual, desvinculando-se os produtos da imagem pessoal da empreendedora e dos pontos de venda.

0 nome da marca é composto por parte do nome da empreendedora "Rosa", que também representa uma flor, que é um elemento forte na cultura, e, também, pelo nome da substância "mel", que caracteriza os produtos. Isso possibilita um nome poético e afetuoso, com grande apelo para o tipo de produto que é comercializado sob a identificação da marca. Portanto, considera-se bem resolvida a parte que cabe a área de Naming. Os produtos gráficos de identificação e comunicação da marca, entretanto, carecem de um projeto de identidade visual capaz de oferecer-lhes unidade expressiva. Em paralelo ao desenvolvimento do projeto de identidade da marca, é necessário ainda o trabalho de recomposição do banco de dados de fornecedores, distribuidores e clientes, com atualização e ampliação das possibilidades de contato, de maneira que a comunicação da marca possa ser incrementada por diferentes meios, além do contato telefônico.

0 conhecimento de endereços eletrônicos, dos fornecedores, distribuidores e clientes, oferece a vantagem adicional de servir como meio de divulgação da marca por meio de mala direta digital, entre outras possibilidades. Do mesmo modo, além de espaço de divulgação da marca, o website também pode e deve ser adaptado como espaço de comercialização dos produtos. 


\section{COMUNICAÇÃO GRÁFICA DA MARCA ROSAMEL: \\ UM ESTUDO DESCRITIVO-INTERPRETATIVO}

\section{Referências}

> AGÊNCIA SEBRAE. Brasil já tem 1,5 milhões de empreendedores individuais. Disponível em: 〈http://www.agenciasebrae.com.br/noticia/12334476/empreendedor-individual/brasil-ja-tem-15-milhao-de-empreendedores-individuais/?indice=10>. Acesso em: $17 / 07 / 2011$.

> BONSIEPE, Gui. Design, Cultura e Sociedade. São Paulo: Editora Blucher, 2011.

> BRASIL. Constituição (1988). Constituição da República Federativa do Brasil: promulgada em 5 de outubro de 1988. Organização do texto: Juarez de Oliveira. 4. ed. São Paulo: Saraiva, 1990. 168 p. (Série Legislação Brasileira).

> GIMENO, J. M. I. La gestión del diseño en la empresa. Madrid: McGraw Hill, 2000.

> CHAN KIM, W. e Mauborgne, R. A Estratégia do Oceano Azul. Rio de Janeiro: Editora Campus. 2005.

> KOTLER, Philip e KELLER, Kevin L. Administração de Marketing. São Paulo: Pearson Prentice Hall, 2006.

> LAKATOS, E., MARCONI, M. Metodologia Científica. São Paulo: Atlas, 1991.

$>$ MARTINS, José R. Branding: um manual para você criar, gerenciar e avaliar marcas. São Paulo: Negócio, 2006.

> MESTRINER, Fábio. Design de Embalagem. São Paulo: Editora Makron Books. 2002

> MOZOTA, Brigitte Borja de. Cestão do Design. Porto Alegre: Bookman, 2011.

> PEÓN, Maria Luísa. Sistemas de identidade visual. Rio de Janeiro: 2AB, 2003.

$>$ PERASSI, Richard L. S. A Visualidade das Marcas Institucionais e Comerciais como Campo de Significação. São Paulo: PUC/SP, 2001 (tese de doutorado).

> ROCHA, Cláudio. Projeto tipográfico: análise e produção de fontes digitais. 3. ed. São Paulo: Rosari, 2005.

$>$ ROSAMEL. Rosamel - Delícias Artesanais. Disponível em: <www.rosameldocesfinos.com. br>. Acesso em: 15/10/2011

> WHEELER, Alina. Design de Identidade da Marca. Editora Bookman, 2008. Disponível em: 〈www.agenciasebrae.com.br/noticias/empreendedor-individual〉. Acesso em: $17 / 07 / 2011$. 
Raquel Gularte Queiroz, Bacharel em Design Gráfico (UDESC, 2005). Especialista em Gestão do Design (UFSC, 2011). Atua com produção de cursos EaD e também é aluna do curso de Licenciatura em Artes Visuais (UDESC).

raquel_q@hotmail.com

Richard Perassi Luiz de Souza, Doutor em Comunicação e Semiótica (PUC/SP, 2001). Atua no curso de graduação em Design e nos programas de pós-graduação em Design e Expressão Gráfica (PóS-DESIGN/UFSC) e pós-graduação em Engenharia e Cestão do Conhecimento (EGC/UFSC).

richard.perassi@uol.com.br

Sharlene Melanie Martins de Araújo, Cursando o Mestrado no Programa de pós-graduação em Design e Expressão Gráfica (Pós-Design/UFSC)

sharlene.melanie@gmail.com 